\section{FOTO CLÍNICA}

\section{Leishmaniasis mucocutánea}

\section{Mucocutaneous leishmaniasis}

\author{
David Loja-Oropeza,' Maricela Vilca-Vásquez ${ }^{2}$ y \\ Bruno Loja-Vilca ${ }^{3}$
}

Loja-Oropeza D, Vilca-Vásquez M, Loja-Vilca B. Leishmaniasis mucocutánea Rev Soc Peru Med Interna. 2018;3।(2):II8.

Varón de 18 años, natural y procedente de Ambo, Huánuco (2060 metros sobre el nivel del mar), con antecedente de leishmaniasis cutánea cinco años atrás, recibió tratamiento que no recuerda. Acude a la consulta por disnea, disfonía y rinorrea mucopurulenta de seis meses de evolución.

Al examen, lesión ulcerocostrosa deformante y destructiva de la pirámide nasal y úlceras costrosas en la región malar y pabellón auricular (Figura 1).

En el frotis de las lesiones, coloración Giemsa, se observó la forma amastigota del parásito. Se inició tratamiento con anfotericina B con mejoría parcial. No acudió a sus controles.

La leishmaniasis es una enfermedad causada por una de las especies de Leishmania, trasmitida por mosquitos del género Lutzomyia. En Perú son cinco las especies que causan la enfermedad: $L$. peruviana, L. lainsoni, $L$. amazonensis, L. guyanensis y L. brasiliensis. Las tres últimas causan la forma mucocutánea de la enfermedad. ${ }^{1}$

El Minsa, en Perú, reportó, 6821 casos de la forma cutánea y 607 casos de la mucocutánea en 2016, de los que 321 procedían de Huánuco. Otros departamentos de alta prevalencia son Áncash, Cusco, Madre de Dios, Piura, Cajamarca, Junín, Ucayali, Lima y Amazonas. En 2018, hasta la semana 5 se habían confirmado 218 casos: 202 cutáneos y 16 mucocutáneos. ${ }^{2,3}$ La evolución de la forma cutánea a mucocutánea suele asociarse con estados de inmunodepresión. Las mucocutáneas producen lesiones mutilantes, que requieren un manejo multidisciplinario ${ }^{4,5}$

I. Médico Internista. Hospital Nacional Arzobispo Loayza. Lima

2. Médico-cirujano. Policlínico EsSalud San Luis. Lima.

3. Estudiante de Medicina Humana. Universidad San Martín de Porres.
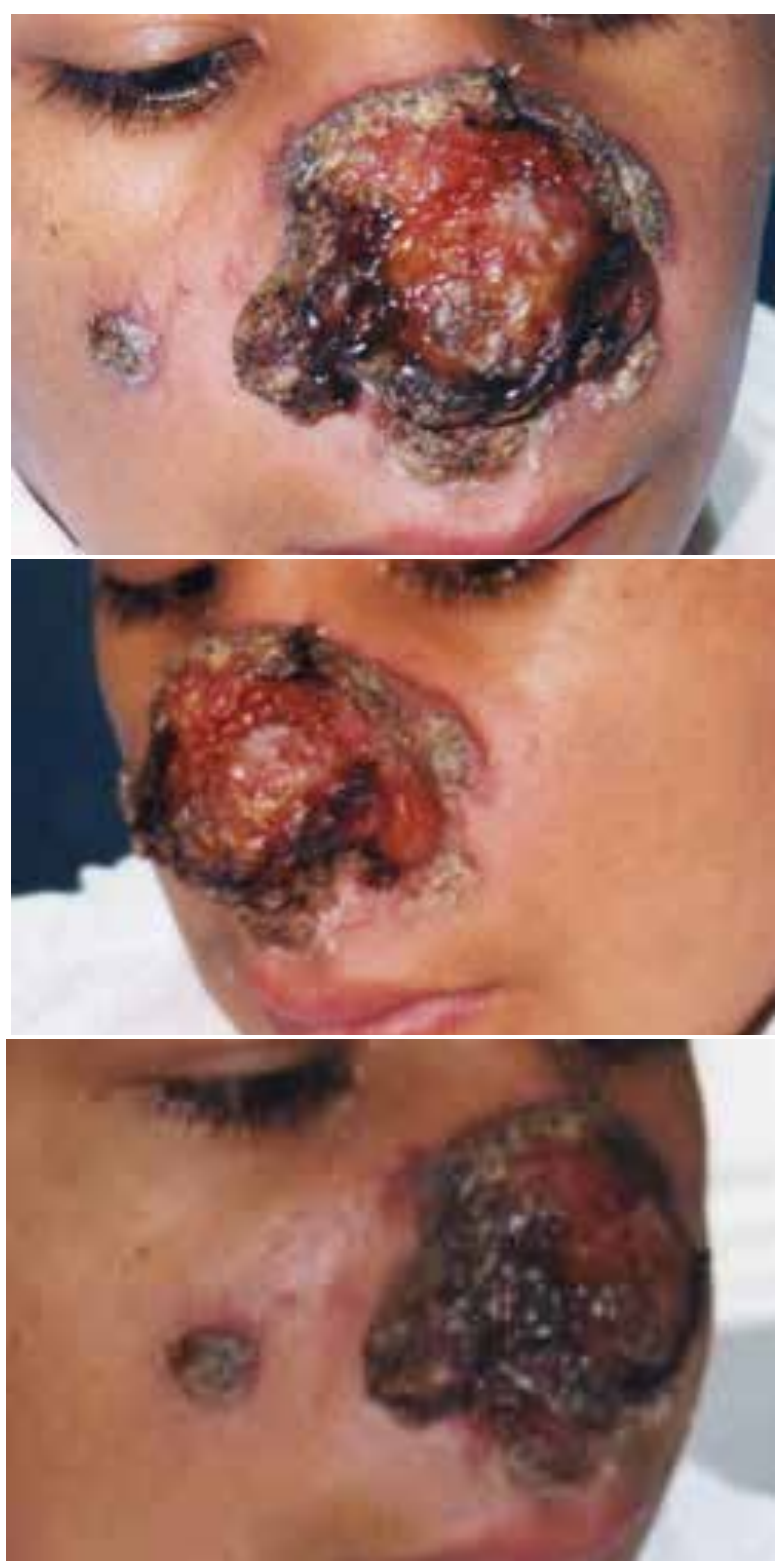

Figura I. Lesión ulcerocostrosa deformante y destructiva de la pirámide nasal y úlceras costrosas en la región malar y pabellón auricular.

\section{REFERENCIAS BIBLIOGRÁFICAS}

I. Hashiguchia Y, Gomez EA, Cáceres AG, Velez LN, Villegas NV, Hashiguchi $\mathrm{K}$, et al. Andean cutaneous leishmaniasis (Andean-CL, uta) in Peru and Ecuador: the causative Leishmania parasites and clinico-epidemiological features. Acta Tropica. 2018; 177:135-145.

2. Centro Nacional de Epidemiologia, Prevención y Control de Enfermedades, Minsa. Hasta la SE 5 de 2018.

3. Norma Técnica. Diagnóstico y Tratamiento de la leishmaniasis en el Perú. Lima, diciembre de 2005.

4. Sandoval A, Minaya G. Leishmaniasis tegumentaria, una mirada a una enfermedad tropical desatendida. Rev Peru Med Exp Salud Publica. 201 I; 28:560-3.

5. Montenegro-Idrogo J], Montañez-Valverde RA, Chian C, Benites Villafane C. Leishmaniasis mucocutánea en un paciente con infección porVIH. Rev Chil Infectol. 2014;31: 610-614. 